\title{
Cluster Formation Mechanism with Bacteria Optimization Method using Cognitive Radio Based Vehicular Ad-Hoc Network
}

\author{
Priya Bakshi, Payal Patial, Prabhat Thakur
}

\begin{abstract}
The growing demand of the radio spectrum is an important part in the multi-agent intelligence management system of the vehicles. Cognitive radio is used for reducing the restricted access to the wavelength of the spectrum and utilizing the radio spectrum is dynamic allocation method. With the advent in the cognitive radio arrangement, the $C R$ in vehicular ad hoc networks allow the operator to sense and hop from one to another system network in the desired frequency of the spectrum based on the environment of the cognitive radio. In existing method implemented a cluster formation mechanism used for data transmission one to another vehicle nodes. In this mechanism used CR-VANET network is divided into subgroups or clusters and achieve accuracy rate among vehicles. In this work, has implemented a cluster formation mechanism with Bacterial foraging optimization algorithm method in Cognitive radio in VANETs. In planned technique a self-motivated system network is established on the basis of clusters using BFOA network goals to achieve better throughput in data transmission one node to another node with RSU (Road Side Units). In the experimental result improves accuracy of the data transmission over the network. In proposed research, vehicles and road side units are deployed in the network. When there is loss of the data packets during the transmission in the network, then optimized clustering phase has implemented. In addition, the selections of the cluster heads are maintained the path and optimization (BFOA) phase implement to recover the path losses and improve the network performance such as overhead, energy consumption, E2E delay and Network Throughput and compared with existing method (Cluster-Formation). Simulation tool used in this proposed work is MATLAB $2016 a$.
\end{abstract}

Index Terms: Cognitive radio, Radio Spectrum, Vehicular ad-hoc network and Bacteria Foraging Optimization algorithm.

\section{INTRODUCTION}

Cognitive radio is the method of the modification and arrangement of the network used for the remote directional region. Remote sensing is the identification of the remote sensing at that region where remote sensing area leads to alteration in the transmission range or the changeability of the desired range [1]. The characterization of the extension of the radiological features, wide investigating range for detection of optional radio [2]. The main challenge is the detection of physical radio in projecting range recognizing devices and computational for detection of data between central node. It is

Revised Manuscript Received on July 05, 2019.

Priya Bakshi, M.E student, Department of Electronics \& Communication Engineering, Chandigarh University, Gharuan.

Payal Patial, Department of Electronics \& Communication Engineering, Chandigarh University, Gharuan.

Prabhat Thakur, Department of Electrical and Electronics Engineering, University of Johannesburg, S.A. described that searching of the development of the flag closeness, increased development of the detection technique and requirement of data required among central node. The extension in the amount of the contribution of the central node reduces the presence of the fake identity. A VANET is characterized as an unconstrained impromptu system framed over vehicles preceding onward the street. Such a system can be shaped between vehicles with vehicle to vehicle (V2V) communication or among vehicles and framework with vehicle-to arrangement (V2I) correspondence [2] [3] [4]. Such VANETs in which vehicles can speak with one another and furthermore with roadside framework give a way to progress street security by empowering various possible benefits for driver help, crash cautioning, traffic data, and checking [5] [6]. The accessibility of different applications will improve street security and vehicular condition. In perspective on this, utilizing cognitive radio (CR) innovation in vehicular ad hoc networks will authorize progressively productive radio range operation and, thus, improve vehicular correspondence effectiveness [7] [8] [9]. Range use approximations throughout the years have demonstrated a wasteful range delivery and utilization with numerous unused or in usage authorized groups over various reality, for instance, range groups for TV broadcasting, bringing about extensive range wastage [10] [11]. Thus, administrative offices, for example, FCC [12] in the USA that manages range portions, have now opened the authorized groups to unlicensed/auxiliary client (SU) using CR [13] [14] [15] so as to empower an increasingly productive utilization of the range groups [16].

\section{A. Problem Formulation and Research Role}

In CR network, the hidden terminal problem where the $\mathrm{CR}$ might transmit signals in the corresponding primary user band causing interference to the nearby primary receiver which is related to degradation of the network and also the sensing is too fast that it loses the number of bits in the CR network. So these problems must be overcome the high network lifetime [17] [18]. The energy consumption is getting high due to increasing overhead in the network, which is one of the main issues in decreasing throughout of the network, so this also must take care in an efficient way for removal of this gap [19]. In this paper we survive with already described problem by contributing with a solution of utilising bacterial foraging optimisation algorithm for optimizing the performance of the system network. 


\section{LITERATURE SURVEY}

Numerous scientists have set up their work in past research area of psychological radio based VANET. In an investigation [20], research CRAVE: Cognitive Radio empowered Vehicular correspondence in heterogeneous remote frameworks. Vehicular clients were considered as unlicensed/optional clients and were equipped for detecting, breaking down and getting to the range openings powerfully.

Presently days the quick headway of remote correspondence, Cognitive Radio for vehicular Ad Hoc systems has gotten gigantic consideration from analysts [21]. Because of the consistently expanding interest for progressively radio range, Cognitive Radio Networks is a one of the answer for this emergency. Security is the one of the essential issue to actualize a superior CRN. CRN is built up in an open correspondence condition that is the reason CRN are more powerless against security dangers than wired systems. Black opening assault is a standout amongst the most widely accepted fault in CR-VANETs. In this circumstance as an outcome the procedure of any instance identification seriously influenced. The subjective center nodes can prompt disparities in information investigation and henceforth accompany a wrong report. They have proposed a straightforward plan for acknowledgment of malevolent hub in Black Hole assault in CR-VANET. In their proposed approach, Trusty Dynamic Software Agent (TDSA) which is utilized for every hub in VANETs and offers databases in the memory spaces of the neighboring hubs. We have analyzed the correspondence range $(\mathrm{R})$ and separation between two contiguousness hubs. Along these lines we can distinguish the network of the two hubs and choose the genuine exchange way. After response of harmful hub we change the affected course and a substitute path has proposed. Furthermore, along this we can dispose of shadowy gap assault from CR-VANETs [22].

Subjective radio is crafty correspondence innovation intended to enable unrestricted customers utilize large number of accessed identified information transmission capability[23]. Intellectual radio has as of late pulled in a great deal of research intrigue. Notwithstanding, little research has been finished in regards to security in intellectual radio, while significantly more research has been done on range detecting and portion issues. A narrow minded psychological radio hub can possess all or part of the assets of various channels, restricting other intellectual radio hubs from getting to these assets. Childish intellectual radio assaults are a genuine security issue since they altogether corrupt the execution of a subjective radio system. In this article writers had distinguished another narrow minded assault type in subjective radio impromptu systems and propose a simple and proficient egotistical intellectual radio assault identification procedure, called COOPON, with multichannel assets by helpful neighboring psychological radio hubs.

An exploration paper talks about the major standards of an intelligent radio RF framework. The key focuses required to accomplish a genuine psychological radio device is laid out [24]. The activity of a psychological radio framework is essentially partitioned into two errands. In the primary assignment, an intellectual radio gadget looks and distinguishes any piece of the range that isn't involved. The second assignment comprises of accomplishing an ideal method of correspondence by apportioning the fitting channels to be utilized. In this paper, the RF necessities required to work an intellectual radio gadget are point by point. Such a gadget can embrace one of two situations of a psychological radio framework: the "intertwine" or "underlay" method of activity. For the two situations, a psychological cycle is pursued. This cycle includes the accompanying four stages: (1) watch, (2) choose, (3) act, and (4) learn. A subjective radio motor is in charge of overseeing and incorporating these four capacities together into a solitary psychological radio gadget.

In a work, creators dissected the bundle transmission time in a psychological agreeable radio system (CCRN) where an optional transmitter (SU-Tx) sends parcels to an auxiliary recipient (SU-Rx) with the assistance of an auxiliary hand-off (SR) [25]. Specifically, they accepted that the SU-Tx and the SR are liable to the joint limitation of the breakdown probability of the essential client (PU) and the pinnacle transmits intensity of the auxiliary clients (SUs). On this premise, they examined the effect of the transmit intensity of the PUs and channel mean power on the bundle communication time period of the CCRN. The versatile transmit control portion arrangements for the SU-Tx and SR are considered. All the more critically, analytical pronunciations for the start to finish throughput, start to finish bundle transmission time, and stable condition for the SR task are acquired. Their outcomes demonstrated that the second bounce of the considered CCRN isn't a bottleneck if the channel mean intensity of the obstruction connections of the systems is little.

In this paper, creators structured and tried the execution of a disseminated and versatile asset the administrator's controller, which permitted the ideal abuse of subjective digital radio and soft information/delicate yield information combination in vehicle accessing scheme. The objective is to permit liveliness as well as processing constrained vehicle advanced mobile phones to use the accessible vehicle-to-framework (V2I) WiFi associations for performing traffic offloading toward area or remote mists by deftly agreeing to an unearthly restricted remote spine developed by various roadside units (i.e., cloudlets) [26] They threw the asset the executives issue into an appropriate obliged stochastic system utility boost issue and infer the ideal psychological asset supervisor that allocates the input time period of the windows by side of road side units, associated with input rates and traffic data packets on VANET clients. The building of the base station presents the firm excellence user to cloud specialist on each open statistics.

Moreover, it had the capacity to gain setting data about the at present accessible transmission capacity vitality assets to rapidly adjust to the versatility instigated unexpected changes in the condition of the vehicular system.

In this paper, a psychological radio cognitive radio (CR) connects with various range groups accessible for optional clients (SUs) are considered. For the SU's dynamic range band choice, two criteria are created. One is to choose the

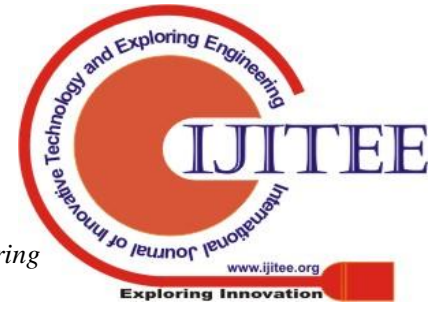


band with the most noteworthy optional channel control gain, and the other is to choose the band with the least impedance channel control increase to essential clients (PUs) [27]. With the excellence of QoS prerequisite concerning delay, the viable limit (EC) observes above optional connections are examined for the two criteria under two range sharing limitations. To start by displaying full advantages in these criteria, the imperative forced on the auxiliary transmitter (ST) is the normal impedance constraint to PUs as it were. In addition, transmitter was mandatory plan for the actual impedance factor of the primary users for the controlling of the transmitter controlling system. For either imperative, they define the ST's ideal transmit governor distribution to augment the SU's EC with both band-choice criteria and, correspondingly, acquire the option AL's capacity percentage and maximum extreme EC in shut structures. Numerical consequences determined substantiate the legitimacy of our determinations and give a useful asset to the range band choice in CR scheme along with different groups accessible.

In an exploration security issue is additionally raised. The Byzantine assault in friendly range detecting, otherwise called the range detecting data noise Spectrum Sensing Data Falsification attack (SSDF) assault in the writing, is one of the key enemies to the achievement of intellectual radio systems (CRNs) [28]. Over t recent years, the examination on the Byzantine assault and protection techniques has increased overall expanding consideration. In this paper, we give a thorough study and instructional exercise on the ongoing advances in the Byzantine assault and resistance for CSS in CRNs. In particular, writers first quickly exhibited the starters of CSS for general per users, including signal identification procedures, theory testing, and information combination. Second, we propose a scientific categorization of the current Byzantine assault practices and expand on the relating assault parameters, which figure out where, who, how, and when to dispatch assaults. At that point, from the viewpoints of homogeneous or heterogeneous situations, they ordered the current safeguard calculations, and give an inside and out instructional exercise on the cutting edge Byzantine guard plans, usually known as strong or secure CSS in the writing. Besides, they examined the lance and-shield connection among Byzantine assault and resistance from an intelligent amusement hypothetical viewpoint. In addition, we feature the unsolved research difficulties and delineate the future research bearings.

This paper considers a psychological radio system in which every auxiliary client chooses an essential client to aid request to get an opportunity of getting to the essential client channel. Accordingly, each gathering of optional clients helping a similar essential client frames an alliance [29]. Inside each alliance, consecutive handing-off is utilized, and a transfer requesting calculation is utilized to utilize the transfers in a proficient way. It is expected at that point to locate the ideal arrangements of auxiliary clients helping every essential client with the end goal that the entirety of their rates is expanded. The issue is detailed as an alliance arrangement diversion, and a Gibbs Sampling based calculation is utilized to locate the ideal alliance structure.

Creators explored the essential client copying Primary User Emulation (PUE) assault, which is a genuine security issue in Cognitive radio (CR) systems. There exist three sorts of PUE aggressors: 1) an egotistical one, which goes for boosting its narrow minded utilization of channel asset; 2) a malevolent one, which focuses for blocking the task of CR system; and 3) a blended one, which is between a childish and noxious PUE assailant. For fighting a narrow minded PUE assailant, a channel observation process must be executed so as to decide lively client's distinguishing proof thus childish PUE aggressor [30]. Additional detecting procedure must be actualized for watching new chances to get to the channel thus for alleviating the malevolent PUE aggressor's impact. Important systems for sending the above procedures are gotten through a diversion hypothesis based examination and the presentation of Nash equilibrium (NE). They demonstrated the NE emphatically relies upon the system request, the accessibility of the range asset, and the sort of the aggressor.

This research [31], determined about the mobile controlling strategy of the system network related to the native and hands off Controlling of the system. Hands off controlling system helps in the continuation of the movable point alteration network stations. Native controlling related to the position of the movable pint for the transmission of the message. Further network system; associate the network users and movable controlling system with increasing value. In present system, novel accessing location and storage alterations are considered the network availability. The required position of user system determine through network on the basis of the distribution of data with less overhead. In this research, novel tracking method related to spatial features on choice control system. The related positions are calculated by inquiring geographical data scheme. They utilize background fuzzy mapping as spatial system related to geographical condition. The proposed approach is demonstrated on the basis of the data set inquiries overhead in simulation results.

In an esteemed research [32], they have presented software cognitive radio network strategy. The main approach of the intellectual result visualization of the already configured coordination and software related $\mathrm{CR}$ component demonstrate the configured design of radio system. The projected method structure determines the efficient approach of the configured information in the network system that may be stable or mobile network. In the meantime, architecture of system network was again configured. This approach determines the actual establishment and have crucial role in the presentation of the related background in investigation of the already configured challenges in movable point and controller node. It was believed that main conceptualization aids to communication technical companies in many facilities, establishment and again configuring of the current and proposed movable system networks.

Table 1: Literature survey highlights table.

\begin{tabular}{|l|l|l|l|}
\hline $\begin{array}{l}\text { N } \\
\text { o. }\end{array}$ & Author & Title & Highlight \\
\hline 1 & $\begin{array}{l}\text { Rawat, Zhao, } \\
\text { Yan and Song } \\
{[20]}\end{array}$ & $\begin{array}{l}\text { CRAVE: } \\
\text { Cognitive radio } \\
\text { enabled vehicular } \\
\text { communications } \\
\text { in heterogeneous } \\
\text { networks. }\end{array}$ & $\begin{array}{l}\text { CRAVE } \\
\text { using three } \\
\text { state } \\
\text { models for }\end{array}$ \\
\end{tabular}


Cluster Formation Mechanism with Bacteria Optimization Method using Cognitive Radio Based Vehicular Ad-hoc Network

\begin{tabular}{|c|c|c|c|}
\hline 2 & $\begin{array}{lr}\text { Mitra, jana } \\
\text { and } & \text { Paray } \\
{[21]} & \end{array}$ & $\begin{array}{l}\text { A novel scheme to } \\
\text { detect and remove } \\
\text { black hole attack } \\
\text { in cognitive radio } \\
\text { vehicular ad hoc } \\
\text { networks } \\
\text { (CR-VANETs). }\end{array}$ & $\begin{array}{l}\text { Security } \\
\text { against } \\
\text { assaults in } \\
\text { CRN } \\
\text { using } \\
\text { TDSA. }\end{array}$ \\
\hline 3 & $\begin{array}{l}\text { Yadav and } \\
\text { Rathi [22] }\end{array}$ & $\begin{array}{l}\text { Spectrum Sensing } \\
\text { Techniques: } \\
\text { Research, } \\
\text { Challenge and } \\
\text { Limitations. }\end{array}$ & $\begin{array}{l}\text { Challenge } \\
\text { and } \\
\text { techniques } \\
\text { in } \\
\text { Spectrum } \\
\text { sensing in } \\
\text { CRN }\end{array}$ \\
\hline 4 & $\begin{array}{l}\text { Mohapatra, } \\
\text { Mohapatra } \\
\text { and Linka } \\
{[23]}\end{array}$ & $\begin{array}{lr}\text { III. } & \text { PERFORMAN } \\
\text { CE } & \text { EVALUATION } \\
\text { OF } & \\
\text { CYCLOSTATIONAR } \\
\text { Y } & \text { BASED } \\
\text { SPECTRUM } & \\
\text { SENSING } & \text { IN } \\
\text { COGNITIVE } & \text { RADIO } \\
\text { NETWORK. } & \end{array}$ & $\begin{array}{l}\text { Assault } \\
\text { Identificat } \\
\text { ion called } \\
\text { COOPON }\end{array}$ \\
\hline 5 & $\begin{array}{l}\text { Kapoor and } \\
\text { Singh [24] }\end{array}$ & $\begin{array}{l}\text { IV. NON-COOPE } \\
\text { RATIVE SPECTRUM } \\
\text { SENSING: A } \\
\text { HYBRID MODEL } \\
\text { APPROACH. }\end{array}$ & $\begin{array}{l}\text { Four stage } \\
\text { CRN with } \\
\text { RF frame } \\
\text { work. }\end{array}$ \\
\hline 6 & $\begin{array}{l}\text { Waleed, } \\
\text { Nazam, Seok } \\
\text { and Hyung } \\
{[25]}\end{array}$ & $\begin{array}{l}\text { V. I3S: } \\
\text { INTELLIGENT } \\
\text { SPECTRUM } \\
\text { SENSING SCHEME } \\
\text { FOR COGNITIVE } \\
\text { RADIO NETWORKS. }\end{array}$ & $\begin{array}{l}\text { Intensity } \\
\text { testing } \\
\text { using } \\
\text { CCRN. }\end{array}$ \\
\hline 7 & $\begin{array}{l}\text { Rao, } \\
\text { Karthikeyan } \\
\text { and } \\
\text { Mazumdar } \\
\text { [26] }\end{array}$ & $\begin{array}{l}\text { Energy Detection } \\
\text { Technique For } \\
\text { Spectrum Sensing } \\
\text { in Cognitive } \\
\text { Radio. }\end{array}$ & $\begin{array}{l}\text { Versatile } \\
\text { system of } \\
\text { CRM } \\
\text { manageme } \\
\text { nt. }\end{array}$ \\
\hline 8 & $\begin{array}{l}\text { Juei and } \\
\text { Emad [27] }\end{array}$ & $\begin{array}{lr}\text { An } & \text { Efficient } \\
\text { Multiple } & \text { Lags } \\
\text { Selection } & \text { Method } \\
\text { for } \\
\text { Cyclostationary } \\
\text { Feature Based } \\
\text { Spectrum-Sensing } \\
\text {. }\end{array}$ & $\begin{array}{l}\text { CRN } \\
\text { based } \\
\text { manageme } \\
\text { nt of } \\
\text { various } \\
\text { group of } \\
\text { signal } \\
\text { partners. }\end{array}$ \\
\hline 9 & $\begin{array}{l}\text { Mehta, } \\
\text { Kumar and } \\
\text { Saini [28] }\end{array}$ & $\begin{array}{l}\text { Comparison of } \\
\text { Spectrum Sensing } \\
\text { Techniques in } \\
\text { Cognitive Radio } \\
\text { Networks. }\end{array}$ & $\begin{array}{l}\text { Security } \\
\text { manageme } \\
\text { nt of CSS } \\
\text { and SSDF. }\end{array}$ \\
\hline 10 & $\begin{array}{l}\text { Hemlatha, } \\
\text { Prithviraz, } \\
\text { Jayalalitha, } \\
\text { Thermanzi, }\end{array}$ & $\begin{array}{l}\text { A Survey Report } \\
\text { On Spectrum } \\
\text { Sensing } \\
\text { Techniques }\end{array}$ & $\begin{array}{l}\text { Essential } \\
\text { client } \\
\text { channel } \\
\text { manageme }\end{array}$ \\
\hline
\end{tabular}

\begin{tabular}{|c|c|c|c|}
\hline & $\begin{array}{l}\text { and } \\
\text { Bharadwaj } \\
{[29]}\end{array}$ & Cognitive Radio. & $\begin{array}{l}\text { nt using } \\
\text { auxiliary } \\
\text { client. }\end{array}$ \\
\hline 11 & $\begin{array}{l}\text { Mansoor, } \\
\text { Islam, } \\
\text { Baharun, } \\
\text { Komaki } \\
\text { and } \\
\text { wada [30] }\end{array}$ & $\begin{array}{lr}\text { CoAd: A } & \text { cluster } \\
\text { based } & \text { adhoc } \\
\text { cognitive } & \text { radio } \\
\text { networks } & \\
\text { architecture } & \text { with } \\
\text { broadcasting } & \\
\text { protocol. } & \end{array}$ & $\begin{array}{l}\text { PUE } \\
\text { assault } \\
\text { manageme } \\
\text { nt in CRN. }\end{array}$ \\
\hline 12 & Jamadagi [31] & $\begin{array}{l}\text { Dealing } \\
\text { location } \\
\text { uncertainty } \\
\text { mobile networks } \\
\text { using contextual } \\
\text { fuzzy cognitive } \\
\text { maps as spatial } \\
\text { decision support } \\
\text { systems. }\end{array}$ & $\begin{array}{l}\text { Mobility } \\
\text { manageme } \\
\text { nt using } \\
\text { geographi } \\
\text { cal } \\
\text { informatio } \\
\text { n system. }\end{array}$ \\
\hline 13 & $\begin{array}{l}\text { Ramos, } \\
\text { Madani [32] }\end{array}$ & $\begin{array}{l}\text { A novel generic } \\
\text { distributed } \\
\text { intelligent } \\
\text { re-configurable } \\
\text { mobile network } \\
\text { architecture. }\end{array}$ & $\begin{array}{l}\text { Software } \\
\text { radio in } \\
\text { CRN. }\end{array}$ \\
\hline
\end{tabular}

\section{NETWORK MODEL AND SYSTEM ARCHITECTURE}

The conventional specially appointed systems contained self-composed CRSU, where SUs have the capacity to detect and use accessible free ranges autonomously. Secondary users are area mindful and coincide with primary users. Cognitive radio preparing capability to ascertain possess Cluster Head Determination Factor approval. CRs are additionally mindful of the Cluster Head Determination Factor approximations of their adjacent CRs. The variety of the clusters separates the network from type of identity of system of each controller. Accepted collection of the primary individual where the message of the secondary individual is misplaced. It is determine that a secondary user distinguishes manageable range through detecting free recurrence groups utilizing methods for instance vitality locators, stable extracted feature, or Eigen esteem based element extracted feature [33]. The proposed grouping system is self-ruling to a particular PU action model. Semi-markov ON -OFF scheme is used to access the implementation of the planned machinery system. Semi-markov $\mathrm{ON}-\mathrm{OFF}$ process is demonstrated on each network station for primary user traffic load. The static and unstatic states are dual methods that are observed for each network station. During initiation time of any channel is thought to be a free irregular variable. IIEEE 802.22 standard for the working wavelength of system network is considered, in which secondary users utilizes a open network station artfully and abandons the network station at whatever point PUs nearness is detected. To evade impedance with PUs, it is accepted that a basic obstruction evasion model is available in the framework. Here, there are two handsets in each cognitive radio are considered, where one is utilized for controlling and

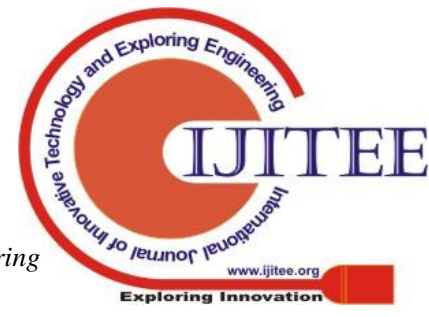


another model is utilized for the information communication. The capacity for minimum exchanging postponement, every handset is range mindful. Equivalent communication extension is considered for all the subjective digital radios. Connection existence among digital radios in the event that they are in one another's correspondence range and offer somewhere around one regular channel. It was additionally accepted that there is a worldwide regular control direct exists in the system.

\section{PROPOSED WORK}

In proposed work has accepted Ad-hoc arrangement design where CRs are self-sort out. The system comprises of primary and secondary user. Frequency range is separated into uncovered symmetry network stations. Discharge's authorized ranges are available to secondary user where primary communications are missing. Secondary user identify primary user and also quantify available range through detecting inactive recurrence groups utilizing strategies, for example, vitality indicators, cyclo stationary include extracted features, or Eigenvalue-based component extraction method [36] [37].

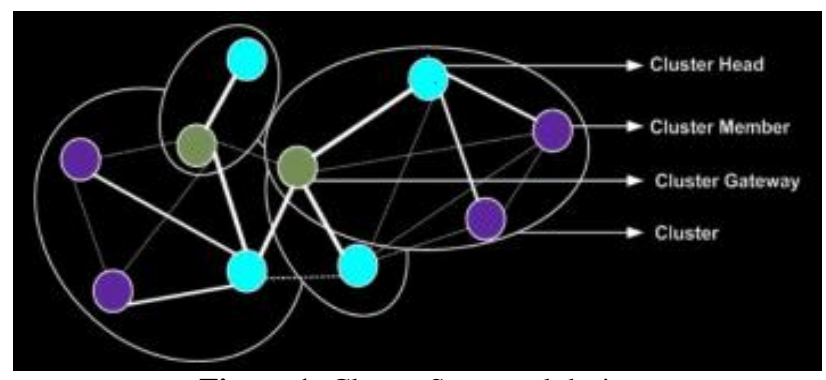

Figure 1: Cluster Structural design

Planned bunching system is automated on a unique essential client action model. Nonetheless, so as to give a systematic assessment of the bunching execution, a semi markov ON -OFF scheme was considered, whereas primary users traffic load is calculated in accordance to semi markov ON - OFF scheme, the circumstance may be $\mathrm{ON}$ or OFF condition[38]. The measurement of every time period is thought to be an autonomous arbitrary inconstant. The assumed value that is normal, wherever the organization of system network is authenticated to automated running primary user. The working recurrence of the framework pursues IEEE 802.22 standard. We accept every CR is furnished along with dual handsets that occur at same time.

Each radio handset is range nimble with least postponed exchanging capacity. For straightforwardness, we accept a similar communication extension for all CRs. In any case, a connection exists, if two cognitive radios are related and there exists something like one regular channel. Additionally expect there is no worldwide regular controller distract in the system.

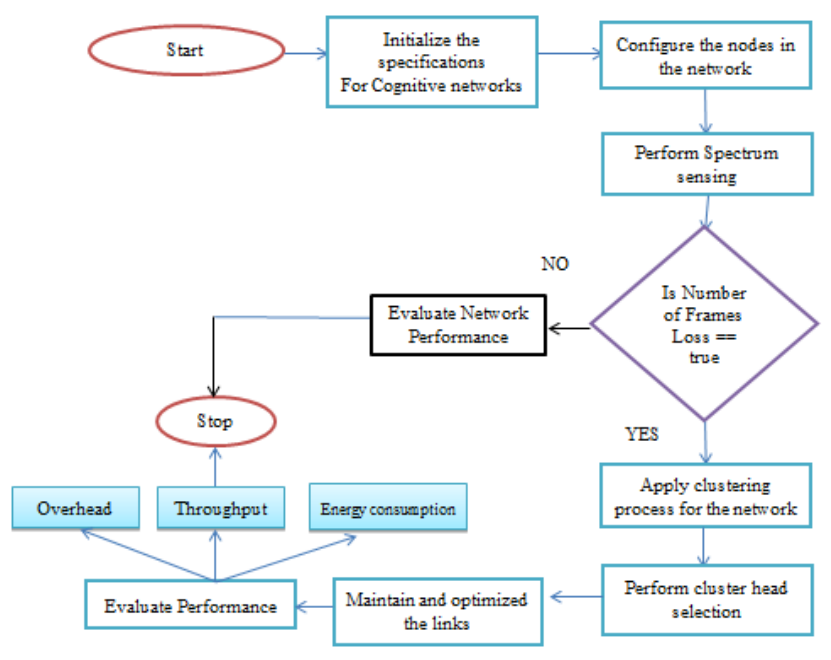

Figure 2. Proposed Flow chart

- Firstly, it will initialize the specification of the network.

- After the initialization we will perform the deployment of the network in terms of vehicles and roadside unit

- Then the spectrum sensing will be applied to the cognitive network

- The frames in terms of the packets will be transferred

- If the frame losses increase, then the clustering process will be implemented and optimized the network performance.

- Then cluster heads will be selected and the maintaining and optimized of the links will be processed.

- Then in the end the performance will be evaluated in terms of energy consumption, throughput and overhead consumption.

- Comparison.

After the group arrangement, $\mathrm{CH}$ decides and place rundown of working frequencies for the bunch. Part hubs at that point verify closest rundown to discover the presence of some other bunch mains in the area. It is searched that part hub turns into the Cluster Gateway and connects the dual groups. In addition, the planned algorithm demonstrates the machine and isolated scheme in various clusters. The figure 1 contains the groups, sun groups and main group. Inside a group, single bounce correspondence presence of cluster members and central node that is related to gateway node. As such, gateway node is related to central node to groups. Correspondence inside a bunching is done by groups utilizing nearby basic network stations. Chronologically, firstly, we will initialize the specification of the network. After the initialization we will perform the deployment of the network in terms of vehicles and roadside unit. Then the spectrum sensing will be applied to the cognitive network. To ensure we have the free positions of the network. The data packets will be transmitted if the frame losses increase, then the clustering process will be implemented and optimized the network performance. Finally, Then cluster heads will be selected and the maintaining and optimized of the links will be processed. Then in the end the performance will be evaluated in form of energy consumption, throughput and overhead consumption. In the last comparison of results will be done. 


\section{Cluster Formation Mechanism with Bacteria Optimization Method using Cognitive Radio Based Vehicular Ad-hoc Network}

\section{EXPERIMENTAL RESULTS}

Compute the clustering performance analysis of the vehicle -2-vehicle of the proposed algorithm, simulation is considered. Various networks simulators are available, whose result predicts of the research model using MATLAB 2016a has been used and performance calculated using SCRIPT language.

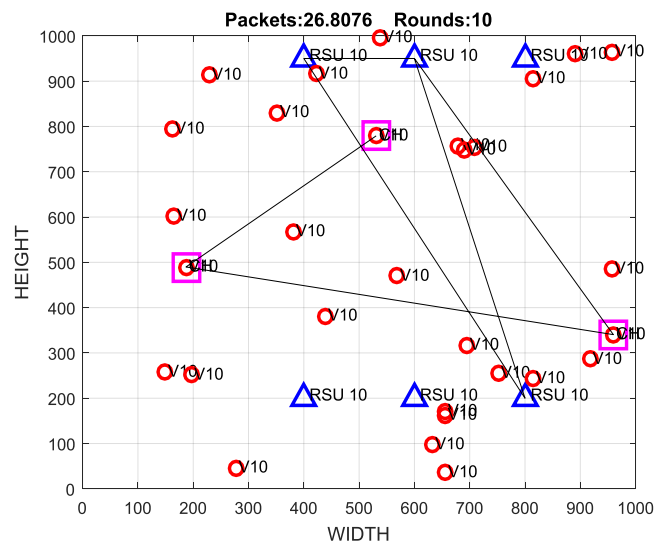

Figure 3: CR-VANET Network Configurations and Cluster mechanism

The figure no. 2 shows the network configuration which deals with the number of vehicles in the red color and Road side units in the blue color. So these are the important configuration to perform the traffic management process. The routing scenario which deals with the transmission process among the road side units and also the network vehicle nodes and shows that in lining how the spectrum is sensing and the routing is performed for the evaluation of the system for the broadcasting of the packets.

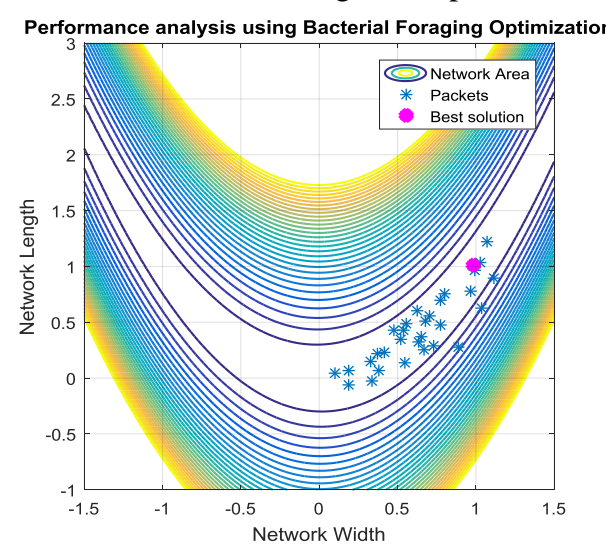

Figure 4: Performance Analysis using BFOA

The figure no. 4 described that the performance analysis using bacteria foraging optimization algorithm. In this proposed work, all vehicle nodes entered in the cognitive radio network. All packets are transferred one node to another node and generate the best solution in the VANET.

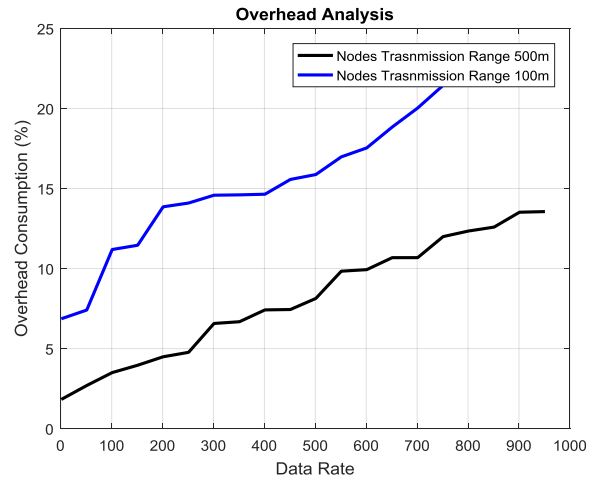

Figure 5: Overhead Consumption with Node transmission Range (100m and 500m) Cluster Formation

The vehicle ad hoc network overhead consumption is defined in terms of \%ge, where the VANET network overhead consumption is desirable to less while developing the clustering formation for the existing network. In this figure the horizontal axes shows about the traffic load and vertical axis defines the network Overhead Consumption.

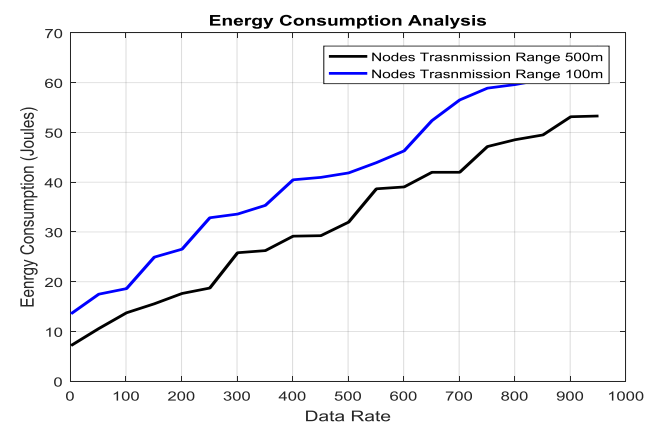

Figure 6: Energy Consumption with Node transmission Range (100m and 500m) Cluster Formation

It is described that energy consumption increase with the increase in flow of information in various significances.

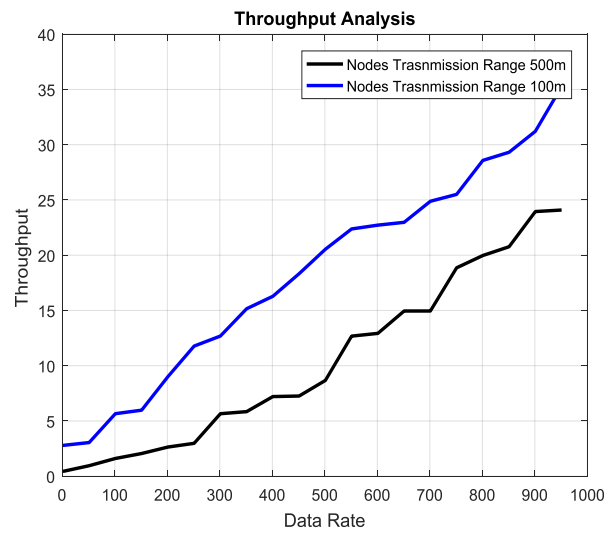

Figure 7: Throughput with Transmission range $100 \mathrm{~m}$ and 500m using Cluster Formation Scenarios

It is shown that throughput increased in both the cases with the increase of the traffic load over the network. Hence, the throughput is increased with the increase in the bandwidth range up to 500 meter instead of the frequency range up to 100 meter for the various flows of the data. 


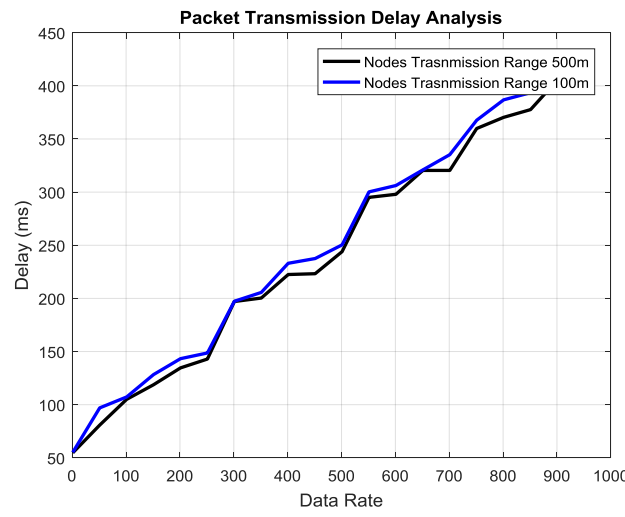

Figure 8: Delay with Communication range $100 \mathrm{~m}$ and $500 \mathrm{~m}$ using Cluster Formation Scenarios

The delay in the transmission rate is less in the network that have the frequency range up to 500 meter than the frequency range at 100 meter at numerous traffic load and run time status defined in vehicle node motivation in system network for data transmission along with identity

Table 2: Performance Analysis with Cluster Formulation Scenario (Existing Work)

\begin{tabular}{|l|l|l|}
\hline $\begin{array}{l}\text { Perfor } \\
\text { mance }\end{array}$ & $\begin{array}{l}\text { Node } \\
\text { Transmissi } \\
\text { on 100 m }\end{array}$ & $\begin{array}{l}\text { Node } \\
\text { Transmissi } \\
\text { on 500m }\end{array}$ \\
\hline $\begin{array}{l}\text { Delay } \\
\text { (ms) }\end{array}$ & 531 & 516 \\
\hline $\begin{array}{l}\text { Overh } \\
\text { ead }\end{array}$ & 26 & 19 \\
\hline $\begin{array}{l}\text { Throu } \\
\text { ghput }\end{array}$ & 70 & 60 \\
\hline $\begin{array}{l}\text { Energ } \\
\text { y (j) }\end{array}$ & 104 & 94 \\
\hline
\end{tabular}

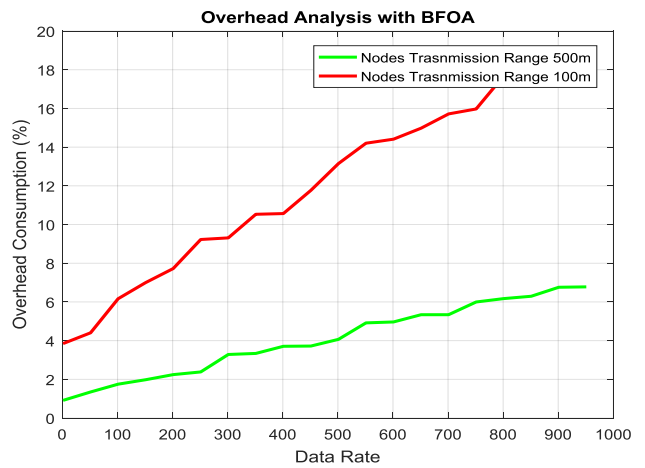

Figure 9: Overhead Analysis with proposed Work

The figure no.9 shows the performance evaluation in terms of the overhead consumption which must below to avoid the traffic collisions of the packets in the network. The above figure shows that the overhead consumption is coming low which increases the lifetime of the network.

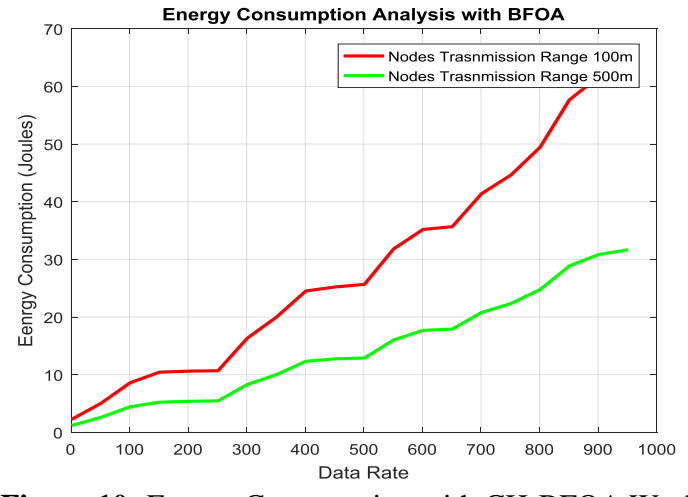

Figure 10: Energy Consumption with CH-BFOA Work

The figure no.10 shows the consumption of the energy and shows that the network is consuming less energy which is efficient and shows that the vehicles are consuming less energy which increases the failure of the nodes in the network. The energy consumption must be low which decreases the chances of the failures in the network and also the increases the network lifetime.

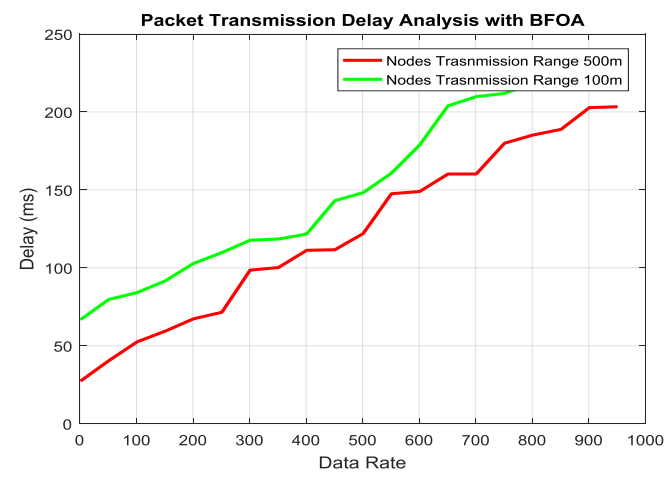

Figure 11: Packet Transmission Delay with Proposed Algorithm

The given figure 11 describes the end to end delay of system network and established system have less delay. The end to end delay must be low and also the end delay should not be increases. If the end delay increases the packet deliveries and broadcasting will be less which corrupted the performance of the network.

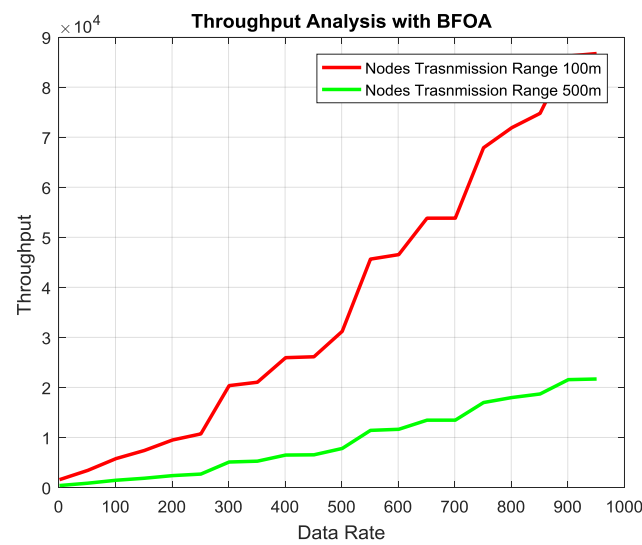

Figure 12: Throughput with Proposed Algorithm

The figure no. 12 shows the consumption of the throughput and shows that the above developed system is able to achieve high throughput of the system network with low

Published By:

Blue Eyes Intelligence Engineering 
energy consumptions. As the throughput increases, the successful delivery of the data packets increased.

Table 3: Performance Analysis with Optimization Scenario

\begin{tabular}{|l|l|l|}
\hline \multicolumn{2}{|c|}{ (Proposed Work) } \\
\hline Performance & $\begin{array}{l}\text { Node } \\
\text { Transmission } \\
\mathbf{1 0 0} \mathbf{~ m}\end{array}$ & $\begin{array}{l}\text { Node } \\
\text { Transmission } \\
\mathbf{5 0 0 m}\end{array}$ \\
\hline Delay (ms) & 312 & 258 \\
\hline Overhead & 17.2 & 8.60 \\
\hline Throughput & 95.3 & 80 \\
\hline Energy (j) & 56 & 78 \\
\hline
\end{tabular}

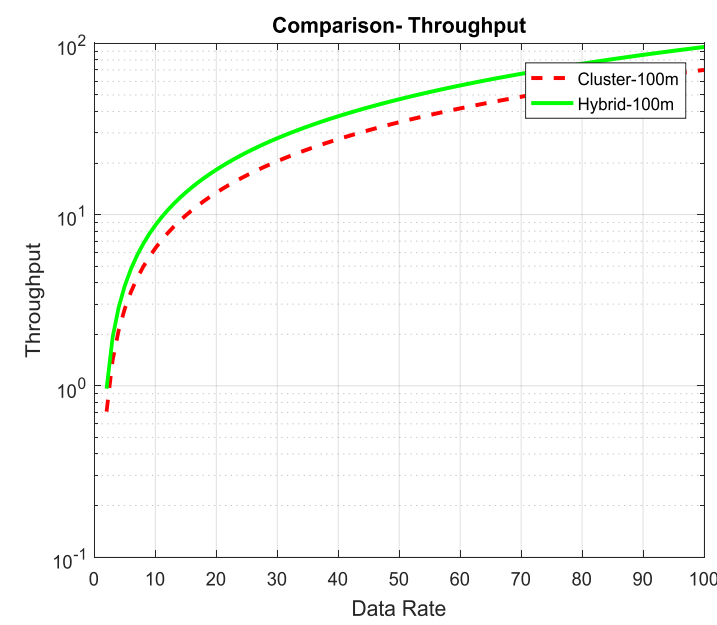

Figure 13 Comparison - Throughput Node Transmission Range with $100 \mathrm{~m}$ range.

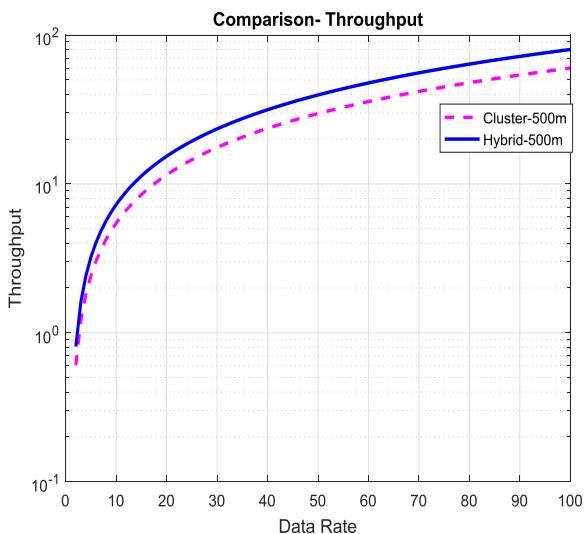

Figure 14: Comparison - Throughput Node Transmission Range with $500 \mathrm{~m}$ range

The network at high frequency range need less number of the vehicle node for transmitting of the data from sender to destination. Whereas, decrease in the amount of vehicle nodes and the number of the connection among the network results in the reducing the rate of again sending of data frames and failure of the connection among the network. The reason is that the throughput for both the case increased with the increment in traffic load over the system network.

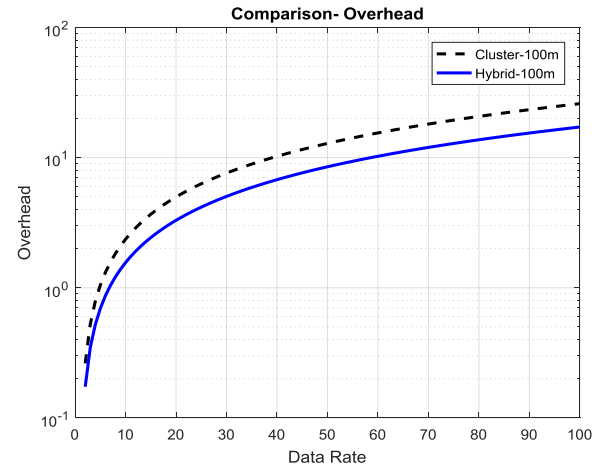

Figure 15: Comparison - Overhead Node Transmission Range with $100 \mathrm{~m}$

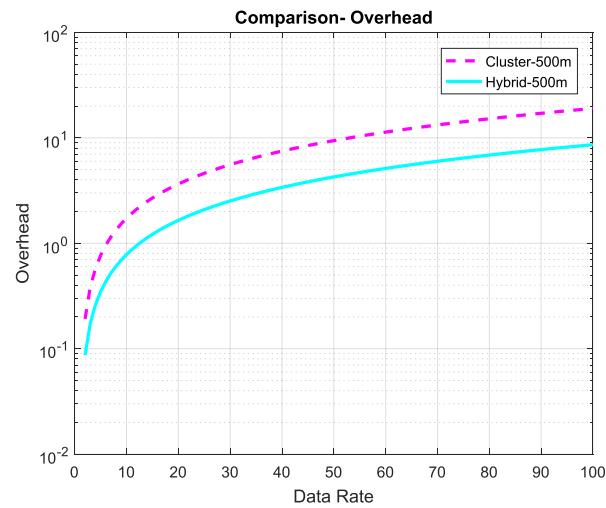

Figure 16: Comparison - Overhead Node Transmission Range with $500 \mathrm{~m}$

The comparative analysis value of the overhead related to vehicle network system in which transmitted data up to 500 meter associated with data transmitted up to 100 meter for various traffic loads in system.

The main aim is that the hops in the system network with the short frequency range need high rate of the communicating nodes for the transmission of the data frames from sender to receiver node than long bandwidth range. The high quantity of the nodes leads to increase in the traffic over the network and data frames are again transmitted due to high capacity of the node where the number of the controlled packets is increased gradually. Therefore, the radio bandwidth range up to 100 meter has more overhead over the network than radio frequency range at 100 meter. 


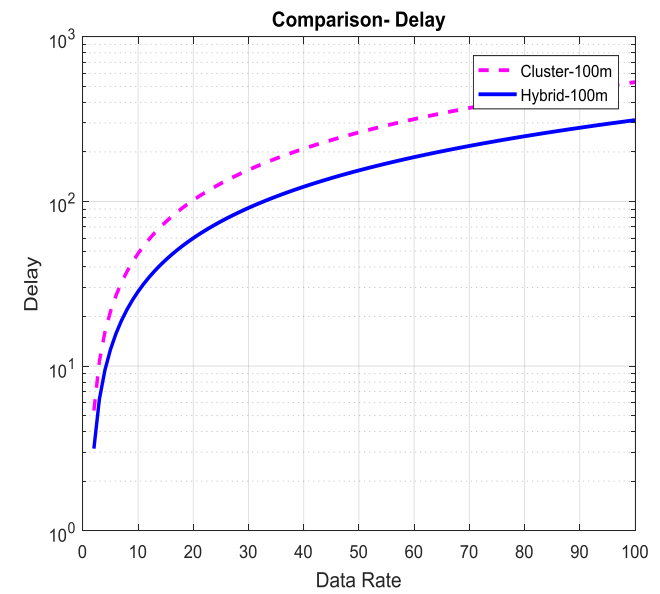

Figure 17: Delay with Node transmission delay range 100m.

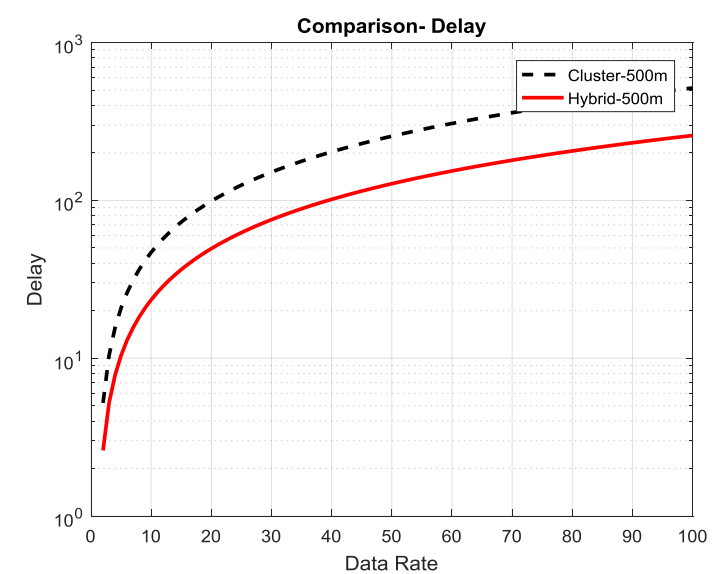

Figure 18 Delay with Node transmission delay range $500 \mathrm{~m}$.

The delay in the rate of transmission over the network is less in frequency range of 500 meter than the bandwidth range of 100 meter through the system network with the traffic load. Amount of the vehicular hop node from sender to destination node at desired transmitted range is reduced related to lesser transmitted range. Therefore, the low amount of the middle nodes forward the information packets over the network that leads to less processed information. Hence, the long frequency transmission range leads to less number the delay in data frames than at minimum frequency transmission range over the network.

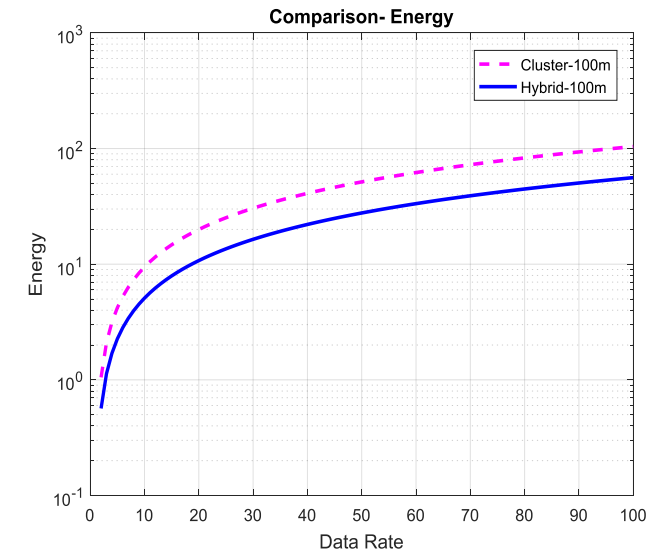

Figure 19: Energy with hop transmission delay range 100m.

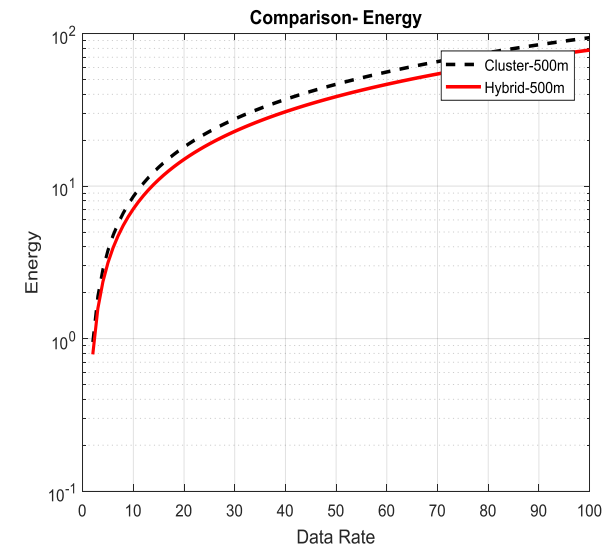

Figure 20: Energy with Node transmission delay range $500 \mathrm{~m}$.

The consumption of energy is less in the network is less in bandwidth range of 500 meter than the frequency range of 100 meter through network with the traffic load. The main aim of the amount of the vehicular node from source to destination at longer transmitted range is reduced as compared to shorter transmitted range.

Table 4: Comparative Analysis

\begin{tabular}{|l|c|c|c|c|}
\hline $\begin{array}{l}\text { Performa } \\
\text { nce }\end{array}$ & \multicolumn{2}{|c|}{ Proposed Work } & \multicolumn{2}{|c|}{ Existing Work } \\
& $\begin{array}{l}\text { Node } \\
\mathbf{T r} \\
\mathbf{1 0 0} \\
\mathbf{m}\end{array}$ & $\begin{array}{l}\text { Node } \\
\mathbf{T r} \\
\mathbf{5 0 0 m}\end{array}$ & $\begin{array}{l}\text { Node } \\
\mathbf{T r} \\
\mathbf{1 0 0} \mathbf{~ m}\end{array}$ & $\begin{array}{l}\text { Node } \\
\mathbf{T r} \\
\mathbf{5 0 0 m}\end{array}$ \\
\hline $\begin{array}{l}\text { 40Delay } \\
\text { (ms) }\end{array}$ & 312 & 258 & 531 & 516 \\
\hline $\begin{array}{l}\text { Overhead } \\
\text { Through } \\
\text { put }\end{array}$ & 17.2 & 8.60 & 26 & 19 \\
\hline $\begin{array}{l}\text { Energy } \\
\text { (j) }\end{array}$ & 56.3 & 80 & 70 & 60 \\
\hline
\end{tabular}

\section{CONCLUSION AND FUTURE SCOPE}

In conclusion, planned approach has semi dynamic network used for information exchanging. For semi-dynamic model, a cluster method and Optimization is defined and validate the performance. In cluster model calculate the CHS (Cluster Head Selection) is depend upon the wts., where to evaluate the weight number of channels and no_of_neighboring vehicle nodes is taken into measured. In this research model metric has been taken into account known as vehicle nodes speed, distance along with the existing two to evaluate weight for each vehicle node. All CMs (Cluster members) are one-hop apart from Cluster Head connects two nearest clusters where there can be two intermediate edge members among two cluster heads. Normally used a local channel, inter cluster communications are performed. After that cluster formation, in proposed work implemented optimization algorithm (BFOA) work with various phases in data transmission. The optimization process is used at time period, when the data is transmitted from one node to another, where the generation of the group routes takes place. Wherever, due the presence of traffic load in the routes 


\section{Cluster Formation Mechanism with Bacteria Optimization Method using Cognitive Radio Based Vehicular Ad-hoc Network}

transmission may not take place correctly. Sometime route break down and lot of loss generated. In proposed system has semi-dynamic network used for information exchanging. For semi-dynamic model, a cluster method and Optimization is defined and validate the performance. In cluster model calculate the CHS (Cluster Head Selection) is depend upon the weights, where to evaluate the weight number of channels and number of neighboring vehicle nodes is taken into measured. In this research model metric has been taken into account known as vehicle nodes speed, distance along with the existing two to evaluate weight for each vehicle node. All CMs (Cluster members) are one-hop apart from Cluster Head connects two nearest clusters where there can be two intermediate edge members among two cluster heads. Normally used a local channel, inter cluster communications are performed. After that cluster formation, in proposed work implemented optimization algorithm (BFOA) work with various phases in data transmission. The optimization process is used at that time, when the data is transmitted from one node to another, where the generation of the group routes takes place. Wherever, due the presence of traffic load in the routes transmission may not take place correctly. Sometime route break down and lot of loss generated.

In future Scope, focused on the authentication and secures system by development of the Security cryptographic and Crossbreed routing rules through range sensed method.

\section{REFERENCES}

[1]Raut, R. and Kulat, K.D., 2011. SDR design with advanced algorithms for cognitive radio. IJACS, 1(4), pp.134-141.

[2]Toor, Y., Muhlethaler, P., Laouiti, A. and De La Fortelle, A., 2008. Vehicle ad hoc networks: Applications and related technical issues. IEEE communications surveys \& tutorials, 10(3), pp.74-88.

[3]Hartenstein, H. and Laberteaux, L.P., 2008. A tutorial survey on vehicular ad hoc networks. IEEE Communications magazine, 46(6), pp.164-171.

[4]Boukerche, A., Oliveira, H.A., Nakamura, E.F. and Loureiro, A.A., 2008. Vehicular ad hoc networks: A new challenge for localization-based systems. Computer communications, 31(12), pp.2838-2849.

[5]Li, F. and Wang, Y., 2007. Routing in vehicular ad hoc networks: A survey. IEEE Vehicular technology magazine, 2(2), pp.12-22.

[6]Marcus, M., Burtle, J., Franca, B., Lahjouji, A. and McNeil, N., 2002. Federal communications commission spectrum policy task force. Report of the unlicensed devices and experimental licenses working group

[7]Luo, J. and Hubaux, J.P., 2006. A survey of research in inter-vehicle communications. In Embedded Security in Cars (pp. 111-122). Springer, Berlin, Heidelberg

[8]Mercier, B., Fodor, V., Thobaben, R., Skoglund, M., Koivunen, V., Lindfors, S., Ryynänen, J., Larsson, E.G., PetriolI, C., Bongiovanni, G. and Grøndalen, O., 2008. Sensor networks for cognitive radio: Theory and system design. ICT mobile summit, pp.10-17.

[9]Force, S.P.T., 2002. Spectrum policy task force report et docket no. 02-135. US Federal Communications Commission.

[10] Zhao, Q. and Swami, A., 2007. A survey of dynamic spectrum access: Signal processing and networking perspectives. CALIFORNIA UNIV DAVIS DEPT OF ELECTRICAL AND COMPUTER ENGINEERING.

[11] Patil, K., Prasad, R. and Skouby, K., 2011, February. A survey of worldwide spectrum occupancy measurement campaigns for cognitive radio. In 2011 International Conference on Devices and Communications (ICDeCom) (pp. 1-5). IEEE.

[12] Federal Communications Commission, 2010. In the Matter of: Unlicensed Operation in the TV Broadcast Bands (ET Docket No. 04-186) and Additional Spectrum for Unlicensed Devices Below 900 $\mathrm{MHz}$ and in the $3 \mathrm{GHz}$ Band (ET Docket No. 02-380). FCC 10-174: Second Memorandum Opinion and Order.

[13] Chen, K.C., Peng, Y.J., Prasad, N., Liang, Y.C. and Sun, S., 2008 January. Cognitive radio network architecture: part I--general structure. In Proceedings of the 2nd international conference on Ubiquitous information management and communication (pp. 114-119). ACM

[14] Nitola III, J., 1999. Cognitive radio: Making software radios more personal. IEEE Personal Communication, pp.13-18.

[15] Mitola, J.I., 2002. Cognitive radio. An integrated agent architecture for software defined radio.

[16] Haykin, S., 2005. Cognitive radio: brain-empowered wireless communications. IEEE journal on selected areas in communications, 23(2), pp.201-220.

[17] Akyildiz, I.F., Lee, W.Y., Vuran, M.C. and Mohanty, S., 2006. NeXt generation/dynamic spectrum access/cognitive radio wireless networks: A survey. Computer networks, 50(13), pp.2127-2159.

[18] Wyglinski, A.M., Nekovee, M. and Hou, T. eds., 2009. Cognitive radio communications and networks: principles and practice. Academic Press.

[19] Eze, J., Zhang, S., Liu, E. and Eze, E., 2017, September. Cognitive radio technology assisted vehicular ad-hoc networks (VANETs): Current status, challenges, and research trends. In 2017 23rd International Conference on Automation and Computing (ICAC) (pp. 1-6). IEEE.

[20] Rawat, D.B., Zhao, Y., Yan, G. and Song, M., 2013, January. CRAVE: Cognitive radio enabled vehicular communications in heterogeneous networks. In 2013 IEEE Radio and Wireless Symposium (pp. 190-192). IEEE.

[21] Mitra, S., Jana, B. and Poray, J., 2016, December. A novel scheme to detect and remove black hole attack in cognitive radio vehicular ad hoc networks (CR-VANETs). In 2016 International Conference on Computer, Electrical \& Communication Engineering (ICCECE) (pp. 1-5). IEEE.

[22] Yadav, N. and Rathi, S., 2011. Spectrum Sensing Techniques: Research, Challenge and Limitations 1.

[23] Mohapatra, S.G., Mohapatra, A.G. and Lenka, S.K., 2013, March. Performance evaluation of cyclostationary based spectrum sensing in cognitive radio network. In 2013 International Mutli-Conference on Automation, Computing, Communication, Control and Compressed Sensing (iMac4s)(pp. 90-97). IEEE.

[24] Kapoor, S. and Singh, G., 2011, February. Non-cooperative spectrum sensing: a hybrid model approach. In 2011 International conference on Devices and Communications (ICDeCom) (pp. 1-5). IEEE.

[25] Sambana, B., Reddy, L.S., Nayak, D.R. and Rao, K.C.B., 2019. Integrative Spectrum Sensing in Cognitive Radio Using Wireless Networks. In Proceedings of International Conference on Remote Sensing for Disaster Management(pp. 613-623). Springer, Cham.

[26] Ebaied, M.A.E.M.K., Salih, M.A.E.Z., Khalid, M.M.O. and Mohammed, O.I.A.A., 2015. Evaluation of Interchangeable Spectrum Sensing Scheduling Algorithm (Doctoral dissertation, Sudan University of Science and Technology).

[27] Shen, J.C. and Alsusa, E., 2013. An efficient multiple lags selection method for cyclostationary feature based spectrum-sensing. IEEE Signal Processing Letters, 20(2), pp.133-136.

[28] Mehta, T., Kumar, N. and Saini, S.S., 2013. Comparison of Spectrum Sensing Techniques in Cognitive Radio Networks 1.

[29] Hemalatha, M., Prithviraj, V., Jayalalitha, S., Thenmozhi, K., Bharadwaj, D. and Girish, G.K., 2012. A survey report on spectrum sensing techniques in cognitive radio. Journal of Theoretical and Applied Information Technology, 37(1), pp.32-38.

[30] Mansoor, N., Islam, A.M., Baharun, S., Komaki, S. and Wada, K., 2013, May. CoAd: A cluster based adhoc cognitive radio networks architecture with broadcasting protocol. In 2013 International Conference on Informatics, Electronics and Vision (ICIEV) (pp. 1-6). IEEE.

[31] Jamadagni, N.S., 2000. Dealing with location uncertainty in mobile networks using contextual fuzzy cognitive maps as spatial decision support systems. In Vehicular Technology Conference Fall 2000. IEEE VTS Fall VTC2000. 52nd Vehicular Technology Conference (Cat. No. O0CH37152) (Vol. 3, pp. 1489-1492). IEEE

[32] Ramos, R.E. and Madani, K., 2001. A novel generic distributed intelligent re-configurable mobile network architecture. In IEEE VTS 53rd Vehicular Technology Conference, Spring 2001. Proceedings (Cat. No. 01CH37202)(Vol. 3, pp. 1927-1931). IEEE.

[33] Yucek, T. and Arslan, H., 2009. A survey of spectrum sensing algorithms for cognitive radio applications. IEEE communications surveys \& tutorials, 11(1), pp.116-130. [34] Sun, H., Nallanathan, A., Wang, C.X. and Chen, Y., 2013. Wideband spectrum sensing 
for cognitive radio networks: a survey. IEEE Wireless Communications, 20(2), pp.74-81.

[34] Motamedi, A. and Bahai, A., 2007, April. MAC protocol design for spectrum-agile wireless networks: Stochastic control approach. In 2007 2nd IEEE International Symposium on New Frontiers in Dynamic Spectrum Access Networks (pp. 448-451). IEEE.

[35] Ariananda, D.D., Lakshmanan, M.K. and Nikookar, H., 2009, May. A survey on spectrum sensing techniques for cognitive radio. In 2009 Second International Workshop on Cognitive Radio and Advanced Spectrum Management (pp. 74-79). IEEE.

[36] Mansoor, N., Islam, A.M., Zareei, M., Baharun, S. and Komaki, S., 2013, December. Spectrum aware cluster-based architecture for cognitive radio ad-hoc networks. In 2013 2nd International Conference on Advances in Electrical Engineering (ICAEE) (pp. 181-185). IEEE.

[37] Zhang, W., Mallik, R.K. and Letaief, K.B., 2008, May. Cooperative spectrum sensing optimization in cognitive radio networks. In 2008 IEEE International Conference on Communications (pp. 3411-3415). IEEE.

\section{AUTHORS PROFILE}

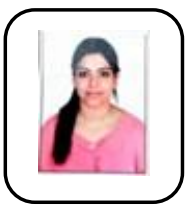

Priya Bakshi received her B.Tech degree in Electronics and Communication Engineering from tawi engineering college, shahpur kandi, pathankot, India in 2017. She is currently a M.E student at Chandigarh University, Punjab, India in the department of Electronics and Communication since 2017. Her areas of interest are Wireless sensor networks, Cognitive Radio and Internet-of-Things.

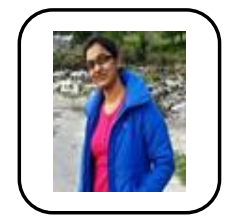

Payal Patial was born in Palampur, Himachal Pradesh, India, in 1989. She received her B.Tech and M.Tech in Electronics and Communication Engineering from Lovely Professional University, Punjab, India in the year 2011 and 2013 respectively. She is working at Chandigarh University as Assistant Professor in Electronics and Communication Engineering since 2013. Her research interest includes Biomedical Signal Processing.

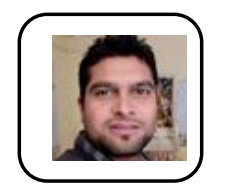

Dr. Prabhat Thakur has received $\mathrm{M}$. Tech and $\mathrm{PhD}$ degree in Electronics and Communication Engineering from the Department of Electronics and Communication Engineering, Jaypee University of Information Technology, Waknaghat, Solan, India in 2015 and 2018, respectively. He worked as Assistant Professor in the Department of Electronics and Communication Engineering, in Gulzar Group of Institutions, Ludhiyana, India from Jul. 2015 to Nov. 2015. Further, he joined as Junior Research Fellow in the Department of Electronics and Communication Engineering, Jay pee University of Information Technology, Waknaghat, Solan , India in Nov., 2015 and has successfully completed project in March 2018. Further, he worked as Assistant Professor in the Department of Electronics and Communication Engineering, Chandigarh University, Chandigarh. Currently, he is working as Post-Doctoral Research Fellow in the Department of Electrical and Electronics Engineering at University of Johannesburg, Johannesburg, South Africa. His current research interests are radio resource management in internet of vehicles, spectrum sharing and throughput enhancement in Cognitive radio communication system. 